\title{
A FAMÍlIA E O ESTADO: ANTÍGONA, HEGEL E AS RAÍZES DO BRASIL
}

\author{
Maikon Chaider Silva Scaldaferro ${ }^{1}$ \\ Instituto Federal do Espirito Santo (IFES) \\ Universidade do Estado do Rio de Janeiro (UERJ)
}

\begin{abstract}
RESUMO:
A partir da leitura hegeliana da tragédia Antígona, apontaremos como a filosofia de Hegel é relevante para a compreensão das relações entre família e Estado na modernidade europeia e na modernidade periférica do Brasil. Para isso, estabeleceremos um diálogo entre o filósofo alemão e os pensadores clássicos que refletiram sobre a nossa identidade nacional.
\end{abstract}

PALAVRAS-CHAVE: Família; Estado; Antígona; Modernidade.

\section{THE FAMILY AND THE STATE: ANTIGONE, HEGEL AND THE ROOTS OF BRAZIL}

\begin{abstract}
:
From the Hegelian reading of Antigone, will point to Hegel's philosophy is relevant to understanding the relationship between family and state in European modernity and in Brazilian peripheral modernity. For this, we will establish a dialogue between the German philosopher and classical thinkers who reflected on our national identity.
\end{abstract}

KEYWORDS: Family; State; Antigone; Modernity.

A caracterização do Brasil como uma civilização culturalmente prémoderna, ou que traz em si os traços de uma modernidade incompleta é um dos traços fundamentais dos clássicos do pensamento social brasileiro do século XX. Esta perspectiva sobre o ethos brasileiro, isto é, sobre as raízes do Brasil, pode ser encontrada nos trabalhos de Gilberto Freyre, Sérgio Buarque de Holanda e Raymundo Faoro. Os três autores elaboram suas reflexões articulando as categorias "família" e "Estado". O modo como "família" e "estado" se relacionam seria a chave de compreensão desse estágio pré-moderno no qual supostamente se encontraria a sociedade

\footnotetext{
${ }^{1}$ Doutorando em filosofia pela Universidade do Estado do Rio de Janeiro (UERJ), Rio de Janeiro - Brasil e Professor do Instituto Federal do Espírito Santo (IFES), Espírito Santo Brasil. E-mail: maikonchaider@ hotmail.com
} 
brasileira. Para entendermos como tais autores construíram tal diagnóstico e discutirmos a validade de suas conclusões, um bom ponto de partida é compreendermos como o pensamento hegeliano contribui para a consolidação do conceito de "modernidade". Um de nossas hipóteses é que um conceito hegeliano de modernidade tem permeado indiretamente, isto é, sem fazer menção a Hegel, as reflexões sobre as "raízes do Brasil".

Habermas esclareceu em $O$ discurso filosófico da modernidade que foi Hegel o primeiro pensador a tomar como problema filosófico a necessidade da modernidade se certificar de si. Hegel colocou propôs a tarefa de "apreender em pensamento o seu tempo" (HABERMAS , 2000, p.25), e isso quer dizer: indicar o princípio dos novos tempos, certificar-se do fundamento da modernidade, apontar de uma perspectiva filosófica o que ela difere de outras épocas. Hegel vai identificar o princípio da subjetividade como o fundamento da modernidade. Defenderemos que é possível compreender como Hegel chegou a essa conclusão por meio da análise de alguns trabalhos do filósofo nos quais ele investigou as relações entre família e Estado. É importante observar que, na interpretação feita por Hegel da tragédia Antígona nota-se uma tentativa de compreender a dinâmica da socialização nas esferas da família e do Estado, bem como a relação tensa entre essas duas instituições. Nossa proposta é primeiramente discutir como Hegel constrói sua leitura da Antígona (I). Já num segundo momento, mostraremos como que os pressupostos da leitura hegeliana da Antígona reaparecem na teoria da modernidade formulada pelo filósofo (II). No terceiro momento do nosso estudo indicaremos como as obras de Freyre, Holanda e Faoro situam o Brasil à margem dessa noção hegeliana de modernidade (III). Ao final discutiremos como pensar o sentido dessa caracterização do ethos brasileiro como algo pré-moderno. Os clássicos do pensamento social brasileiro identificaram a "essência" do Brasil ou só reproduziram uma visão eurocêntrica? (IV).

\section{Antígona: a tensão entre família e Estado}

Hegel faz da sua interpretação da tragédia Antígona o ponto de partida da sua análise dos processos de socialização produzidos no seio da família e do Estado. Antes de reconstruirmo a interpretação hegeliana é preciso esclarecer um conceito fundamental do filósofo de Jena, Sittlichkeit, que costuma ser traduzido por "vida ética", "ética objetiva", "moral objetiva" ou "eticidade". Com o termo Sittlichkeit, Hegel descreveu formas de interação entre os indivíduos em que por meio do exercício da liberdade há a possibilidade de autorrealização individual. O que vai caracterizar a eticidade é que os indivíduos interagem por meio de regras, costumes ou leis e reconhecem a si mesmos nesse conteúdo normativo, reconhecem sua liberdade na norma concretizada. A eticidade "é o conceito da liberdade 
convertido em mundo real e que adquiriu a natureza da consciência de si" (HEGEL, 2005, p. 149).

De acordo com Hegel, a família e Estado são esferas distintas de efetivação da eticidade. Em ambas as esferas haveria um processo de autorrealização e formação dos indivíduos, além de uma interação baseada no reconhecimento de leis, normas e costumes. No entanto, existe uma relação hierárquica entre essas esferas. E para se constituir essa hierarquia o superior deve se efetivar dialeticamente a partir da negação do inferior. ${ }^{2}$ Deste modo, essa hierarquia necessariamente é constituída a partir de uma tensão entre a família e o Estado. Contudo, Hegel considera que antiguidade grega não foi possível uma solução para essa tensão, o mundo antigo (prémoderno) não foi capaz de conciliar a lei particular (família) com a lei universal (Estado). Com isso, ambas as esferas da eticidade entraram em colapso. Hegel vai associar a decadência do mundo grego à mútua destruição dessas esferas da eticidade. Para o filósofo alemão, a tragédia de Sófocles, Antígona, é justamente uma representação artística dessa tensão manifesta no mundo grego.

$\mathrm{Na}$ Antígona, Sófocles narra o destino da filha de Édipo que se vê diante do dilema: obedecer as leis humanas ou as leis divinas? A história começa com a morte dos dois irmãos de Antígona, Eteócles e Polinices, os dois se matam durante uma batalha. Isto ocorre quando Polinices tenta tomar o poder de Tebas das mãos de Eteócles. Com a morte dos dois, quem sobe ao poder é Creonte, tio de Antígona. Nomeado rei, Creonte emite um

\footnotetext{
${ }^{2}$ A primeira coisa que deve ser indicada sobre a dialética hegeliana é que ela é composta por três momentos distintos: tese, antítese e síntese. Segundo o professor Gerd A. Bornheim: "O primeiro momento desse processo - a tese - apresenta-se como uma identidade. Mas o que caracteriza essa identidade inicial é que ela traz em si o não-idêntico, o diferente do idêntico, ou o outro que não o idêntico; desse modo, o positivo só o é aparentemente; pois, em verdade, a identidade inicial contém o negativo [isto é, a antítese]". (BORNHEIM, 1977, p.49). Para explicar isso tomemos um exemplo dado pelo próprio Hegel no prefácio da Fenomenologia do Espírito: um botão de flor é posto positivamente como tese. Entretanto, tal botão já traz em si a negação dele mesmo, a saber, a flor. O botão morre então para vir-a-ser flor. Para Hegel, a antítese não é acrescentada como algo exterior à identidade inicial, a antítese já está presente na própria tese. Entretanto, esse processo não termina nessa contradição, é preciso superá-la. Essa superação da contradição se dá através da síntese, que é a negação da negação. Retomando o exemplo do botão de flor, o quê ocorre agora é que a flor é negada pelo fruto que produz uma síntese dos outros dois momentos. Hegel faz uso do termo Aufhebung, (suprassunção), para tratar desse momento de síntese. O termo Aufhebung deriva do verbo aufheben que significa tanto negar, quanto conservar e elevar. Assim, quando Hegel faz uso do termo Aufhebung para indicar esse momento da síntese, ele não o faz à toa. O que ele pretende afirmar é que a síntese, ao negar aqueles momentos anteriores ela, os conserva, mas eleva$o s$ a uma instância superior. Embora tenhamos dado um exemplo bem simples (do botão de flor) para expormos como se dá o movimento dialético, Hegel pretende identificar como esse processo se dá em toda realidade, seja no desenvolvimento dos seres vivos, nos grandes eventos históricos, no surgimento do Estado e dos regimes políticos, na arte, na religião e até na história da filosofia.
} 
decreto que determina que Polinices não deve ser enterrado nem receber os rituais funerários sagrados, tendo como destino ser devorado pelas aves de rapina, ao contrário de Eteócles, enterrado com honras por ter defendido Tebas dos seus invasores.

$\mathrm{O}$ ato de não enterrar um corpo era algo terrível dentro do universo de crenças dos gregos. Fustel de Coulanges, no seu clássico livro A Cidade Antiga, observa que muito antes do surgimento da religião pública dos gregos havia uma religião privada, praticada somente no seio das famílias. Muito antes de prestarem reverência aos titãs ou aos deuses olimpianos, os gregos realizavam um "culto aos mortos". Tal culto se fundamenta na crença de que um indivíduo morto "[...] continuaria vivendo sob essa terra e nela conservaria o sentimento de bem-estar e de dor" (COULANGES, 2009, p.25). Coulanges observa que

\begin{abstract}
dessa crença primitiva derivou a necessidade da sepultura. Para que a alma fosse fixada nessa morada subterrânea que lhe convinha para a segunda vida, era preciso que o corpo fosse recoberto de terra. A alma que não tivesse o seu túmulo não tinha residência (COULANGES, 2009, p.26).
\end{abstract}

Daí a gravidade do decreto de Creonte, este infligiria ao irmão de Antígona uma punição eterna, "toda a Antiguidade estava convencida de que, sem a sepultura, a alma era miserável, e que pela sepultura se tornava feliz para sempre" (COULANGES, 2009, p.26). Não enterrar um morto atingia diretamente também o destino da família, pois, se a alma do morto estivesse feliz ela tomaria conta da família, trazendo boa sorte para o lar. Por isso, os gregos durante o ano realizavam vários rituais nos quais os mortos recebiam oferendas para levarem uma vida mais confortável no mundo subterrâneo. Esse culto antigo atribuía aos mortos da família o status de divindade. Não é a toa que "os gregos gostavam de dar aos mortos o nome de deuses subterrâneos" (COULANGES, 2009, p. 30), Penates, os deuses do lar, cultuados bem antes de Zeus ou Cronos.

Essas crenças presentes no culto aos mortos, são o pano de fundo que explica o grande dilema apresentado na tragédia de Sófocles: obedecer a lei divina ou a lei humana? A lei divina determinava que todos os rituais funerários deviam ser prestados ao morto, cabendo aos familiares garantirem a ele um sepultamento digno. Diante disso, Antígona contraria o decreto de Creonte e sepulta Polinices. Contudo, ao colocar a lei divina acima da lei do humana, Antígona é punida, sendo sentenciada ao enclausuramento numa caverna. Antígona se suicida antes do cumprimento da sua pena. O suicídio de Antígona acaba trazendo desgraças para Creonte. Primeiro seu filho, que era noivo de Antígona, tenta apunhalá-lo, mas acaba caindo em cima da própria espada e morre. Depois a mulher de Creonte se suicida ao saber da morte do filho. 
No livro Fenomenologia do Espírito, Hegel realiza uma interpretação da Antígona buscando esclarecer a tensão entre família e Estado presente no mundo grego. Na leitura de Hegel, "a lei divina [...] reina na família" (HEGEL, 2002, p. 314), deste modo, Antígona ao contrariar o decreto de Creonte, acaba colocando a eticidade da família acima do Estado, mais do que isso, ela nega a eticidade do Estado ao negar a lei humana. Para Antígona, as leis que regem o lar são universais, imutáveis e superiores a qualquer outra legislação. Vemos isso quando Creonte a interroga, buscando saber se ela realmente sepultou Polinices. Nesse momento Antígona questiona a legitimidade do decreto do Rei:

Eu não creio que teus decretos, escritos pela mão de um mortal, possam ser superiores às leis não escritas e imutáveis dos deuses. Elas não são de hoje nem de ontem, mas são eternas, vigoram em todos os tempos e ninguém sabe quando nasceram Eu tinha para mim que não devia por temor da arrogância de um homem, transgredir essas leis e ser castigada pelos deuses (SÓFOCLES, 2013, p.47).

A "lei da família [...] não está exposta à luz da consciência" (HEGEL, 2002, p.315),isto é, tal lei não é percebida pelo indivíduo como o resultado da ação de um sujeito livre, mas vista como algo que existe desde tempos idos, e por ter sido conservada pela tradição, deve ser praticada. Creonte representa na tragédia grega o defensor da lei humana, a lei da cidade (Estado) "[...] que vigora manifestamente à luz do dia [...]" (HEGEL, 2002, p.313), ao contrário da "lei divina".

Na tragédia Antígona, a lei da família, isto é, a "[...] lei dos deuses antigos, dos deuses subterrâneos" (HEGEL, 2005, p.161) se encontra em tensão com "[...] à lei manifesta, a lei do Estado" (HEGEL, 2005, p. 161). $\mathrm{Na}$ narrativa de Sófocles "essa oposição é a oposição moral suprema, portanto, a mais essencialmente trágica" (HEGEL, 2005, p. 161). Na leitura hegeliana, o desfecho da tragédia é uma representação de como no mundo grego o "[...] destino assustador [...] devora no abismo de sua simplicidade tanto a lei divina quanto a lei humana [...]" (HEGEL, 2002, p.320). A filosofia hegeliana sustenta que esse conflito entre a "lei particular" e a "lei universal", lei divina e lei humana, família e Estado, só encontrou uma solução mediadora durante o desenvolvimento da modernidade europeia.

\section{A dialética da modernidade europeia}

Na leitura hegeliana da tragédia Antígona, a obra de Sófocles é vista como a representação de um conflito insustentável entre família e do Estado existente na antiguidade. Nesse conflito é possível identificar o elemento que será a gênese da decadência do mundo grego: o despontar do princípio da subjetividade. O princípio da subjetividade comporta quatro 
pontos: a) individualismo: a ideia de que o indivíduo é dotado de uma singularidade única; b) direito à crítica: aquilo quer ser visto como universal deve ser reconhecido como legítimo para cada um, portanto precisa estar aberto a críticas; c) autonomia: a ideia de que a consciência humana é livre e dá leis a si mesma; d) idealismo: a ideia de que a própria consciência humana deve ser um objeto de estudo.

O princípio da subjetividade se manifesta tanto no agir de Creonte quanto no agir de Antígona. Tio e sobrinha negam uma das esferas da eticidade na qual eles estão inseridos para afirmarem suas liberdades subjetivas. Antígona nega a eticidade do Estado, já Creonte nega a eticidade da família. Para Hegel, tal movimento na tragédia mostra que a Grécia ainda não era capaz de efetivar historicamente a noção de liberdade subjetiva.

Justamente a liberdade subjetiva, que determina o princípio e a forma característica da liberdade em nosso mundo - que é fundamento absoluto de nosso Estado e de nossa vida religiosa -, significou para a Grécia a ruína. (HEGEL, 2008, p.211).

A efetivação do princípio da subjetividade só se dará na modernidade, por meio de um processo dialético que tem a família como tese, a sociedade civil como antítese e o Estado como síntese. Princípios da Filosofia do Direito é um dos escritos no qual Hegel procura explicar esse processo.

Em sua argumentação Hegel classifica a família como a primeira esfera da eticidade que os indivíduos integram. Para o filósofo, "[...] a família determina-se pela sensibilidade que é una, pelo amor, de sorte que a disposição de espírito correspondente é a consciência própria da individualidade nessa unidade" (HEGEL, 2005, p.156). Entendida como esfera de interação intersubjetiva, a família tem o amor como o médium de comunicação entre os sujeitos. Isto significa, o amor é o meio que permite aos indivíduos se reconhecerem fazendo parte de uma mesma unidade. $\mathrm{Na}$ família o que está em jogo não é um reconhecimento de si como pessoa jurídica, mas sim um reconhecimento de si como um ser carente, que demanda afetividade de outros. Nota-se que o conceito hegeliano de amor pretende descrever os "impulsos primordiais", ou os "sentimentos naturais" resultantes da "carência" constitutiva da espécie. A demanda por cuidados é o primeiro elemento que conduz os indivíduos à socialização ainda quando recém nascidos. Tal carência primária seria suprida pela instituição denominada "família". Por isso Hegel chega a se referir a família como eticidade "imediata" ou "natural".

Por meio da categoria "família", Hegel descreve uma forma de interação social em que as relações de reconhecimento mútuo se operam basicamente no nível da afetividade. Mas essa forma de interação já contém o gérmen da sua dissolução no processo de criação dos filhos. De acordo 
com Hegel, a educação oferecida no núcleo familiar tem um duplo destino. Primeiramente um destino positivo em que a

[...] a moralidade objetiva [eticidade] é introduzida neles [os filhos] como a forma de uma impressão e sem oposição, a alma vive a primeira parte da sua vida neste sentimento, no amor, na confiança e na obediência como fundamento da moral (HEGEL, 2005, p. 164).

Depois a educação tem um destino negativo,

[...] o de conduzir as crianças desde a natureza imediata em que primitivamente se encontram para a independência e a personalidade livre e, por conseguinte, para a capacidade de saírem da unidade natural da família (HEGEL, 2005, p. 164).

A família, enquanto primeira esfera da eticidade produz a propriedade, entendida aqui como o suporte material para a manutenção e conservação da unidade familiar. No entanto, a educação dos filhos vai paulatinamente introduzindo neles a consciência de sua subjetividade, de que eles são personalidades livres.

\begin{abstract}
A dissolução moral da família provém do fato de os filhos, ao assumirem a personalidade livre, ao atingirem a maioridade, serem reconhecidos como pessoas jurídicas e tornarem-se capazes, [...], de livremente possuírem a sua propriedade particular (HEGEL, 2005, p.165).
\end{abstract}

Esta consciência da "personalidade livre", da "subjetividade", é o princípio que causa a dissolução da unidade familiar dando origem há uma nova esfera da eticidade, a saber, a "sociedade civil", que é a antítese da família. Hegel estava convicto que tal forma da eticidade só se realizou no mundo moderno. A noção de sociedade civil não existe em sociedades prémodernas. Estas não são capazes de suportar a consciência do princípio da subjetividade.

A sociedade civil se caracteriza por ser formada por um conjunto de indivíduos egocêntricos que buscam satisfazer suas próprias carências, e não ad do grupo que ele está inserido. Nas palavras de Hegel, na sociedade civil "[...] os indivíduos são pessoas privadas que têm como fim seu próprio interesse" (HEGEL, 2005, p. 171). Na sociedade civil o médium das relações de reconhecimento entre os indivíduos são os "interesses individuais". $\mathrm{Na}$ interação social os indivíduos se enxergam como subjetividades egoístas capazes de gerar sua propriedade e que estão em concorrência. Nessa esfera da eticidade os indivíduos tomam consciência que a manutenção dos interesses individuais só pode se realizar na medida em que "algo" universal seja efetivado. Esse universal é o direito positivo, capaz de garantir a proteção dos sujeitos particulares e de suas propriedades. 
"A propriedade fundamenta-se, então, no contrato e nas formalidades que o autenticam e fazem-no juridicamente válido" (HEGEL, 2005, p. 187).

A constituição do direito positivo teria como fim garantir a interação baseada na busca de interesses individuais, aponta para uma questão extremamente importante. Algo importante desse ser ressaltado aqui, acompanhamos Bobbio (1989) quando ele interpreta que o termo sociedade civil utilizado por Hegel não equivale a noção contemporânea de sociedade civil como algo distinto do Estado. Nos Princípio da Filosofia do Direito, Hegel chega a se referir à sociedade civil como "Estado extrínseco" e "Estado da carência e do intelecto". Para nós, parece coerente a interpretação de que a sociedade civil já é o Estado, o Estado em seu sentido mais liberal e individualista, isto é, "[...] entendido precisamente como aparelho jurídico, como conjunto dos meios de natureza jurídica" (BOBBIO, 1989, p.82) que ordena "[...] o mundo das relações econômicas e das relações entre as classes que o sistema econômico produz" (BOBBIO, 1989, p.82).

A sociedade civil também produz no seu interior o elemento de sua negação. A busca desenfreada dos indivíduos para realizarem seus interesses egoístas gera relações econômicas e mercadológicas que produzem um elemento universal, isto é, as normas jurídicas reguladoras dessas relações. No entanto, essa integração social baseada no egoísmo é muito frágil. Pois, o egoísmo da sociedade civil produz cada vez mais o isolamento dos indivíduos e ameaça a existência de uma forma de vida coletiva, já que o próprio mediun que garante essa forma de vida (o direito) pode ser "manipulado" e "desvirtuado" para que sujeitos egocêntricos atinjam seus fins. Em outras palavras, os interesses econômicos subordinam o direito e fragilizam ainda mais uma integração social que já é frágil.

\begin{abstract}
Ora, é bastante conhecido o fato de que Hegel possuía conhecimento suficiente das relações do seu tempo para ver nas estruturas dessa sociedade civil tendências imanentes à desintegração social; com um potencial de previsão que nenhum outro filósofo mostrou em sua época, percebeu os perigos que devem residir na esfera incontrolada do mercado capitalista, uma vez que produz regularmente desemprego e miséria em massa (HONNETH, 2007, p. 139).
\end{abstract}

Essa tendência à desintegração presente na modernidade leva ao desenvolvimento histórico de uma nova esfera da eticidade. Da sociedade civil surge o Estado. Enquanto a sociedade civil é a negação da família, o Estado é a negação da negação. No Estado o indivíduo reconhece a dignidade da "[...] atividade consciente para um fim coletivo" (HEGEL, 2005 , p. 203). O indivíduo reconhece que "[...] ao mesmo tempo, que ele pertence a um todo, que é ele mesmo um membro da sociedade em geral e que seu interesse e esforço se orientam para fins não egoístas desta totalidade" (HEGEL, 2005, p.202). Na eticidade do Estado, a associação 
entre os indivíduos não está voltada para a mera realização de interesses individuais. "A associação como tal é o verdadeiro fim, e o destino dos indivíduos está em participarem numa vida coletiva [...]" (HEGEL, 2005, p. 205). O médium das relações é aqui a "vida universal", a "vida coletiva". Os indivíduos se reconhecem como sujeitos que fazem parte de um todo e realizam ações para a manutenção desse todo. No Estado, o que está em jogo é a ação do indivíduo enquanto cidadão. Nesse caso,

[...] o sujeito individual está incluído no Estado quando for capaz de formar racionalmente suas habilidades, suas disposições e talentos de modo que estes possam ser empregados para o bem universal (HONNETH, 2007, p. 122).

Hegel é um ferrenho crítico de uma visão estritamente liberal do Estado. Com a distinção entre sociedade civil e Estado ele pretende então distinguir dois momentos de realização do Estado,

[...] o Estado jurídico-administrativo, cuja tarefa é regular relações externas, e o Estado ético-político, cuja tarefa é realizar adesão íntima do cidadão ao todo, e que poderíamos chamar - por oposição - de Estado interior ou, com outras palavras , de nexo entre o momento mecânico (individualista) e o momento orgânico (solidarista) na formação do Estado (BOBBIO, 1989, p. 83).

Para Hegel nessa esfera da eticidade ocorre uma síntese entre a família (tese) e a sociedade civil (antítese). Aliás, essa forma de eticidade seria superior às duas anteriores, pois ela permite a realização de uma ideia de liberdade mais ampla. Cabe lembrar que o movimento dialético não elimina as duas esferas da eticidade anteriores, a saber, a família e a sociedade civil. Ambas são conservadas dentro do Estado que atribui a elas um status jurídico, além de regulamentar e preservar o funcionamento mais ou menos "saudável" delas. Para entendermos isso, pensemos aqui no direito da família, ramo do direito que trata das normas jurídicas que preservam a estrutura familiar. Além disso, podemos dizer que o Estado busca preservar o funcionamento da sociedade civil através de leis trabalhistas, o direito empresarial, o direito do consumidor, dentre outras ferramentas capazes de impedir que a briga por interesses egoístas cause a desintegração social.

\section{À margem da modernidade}

Hegel compreende que na modernidade há a consolidação de um modelo de socialização superior à socialização ocorrida no seio da família. Esse modelo de socialização é superior porque é mais universal, mais racional. E Isto significa dizer que, tal modelo de socialização é pautado pelo reconhecimento de todo indivíduo como um sujeito racional e dotado 
de direitos, e não num reconhecimento afetivo de um indivíduo específico que é membro da família.

No pensamento social brasileiro do século XX a dialética hegeliana da modernidade é questionada indiretamente, isto é, sem fazer menções a Hegel. As interpretações clássicas sobre o ethos brasileiro colocaram em dúvida se tal desenvolvimento da modernidade, tal como é interpretada por Hegel, teria ocorrido da mesma forma no Brasil. A "modernidade periférica" brasileira seria distinta da modernidade dos países centrais, de modo que nossa forma de socialização seria mais próxima de uma socialização prémoderna, arcaica. Encontramos esse tipo de interpretação em autores clássicos como Gilberto Freyre, Sérgio Buarque de Holanda e Raymundo Faoro. Tais autores se tornaram referências na investigação da nossa "identidade nacional", isso que Hegel chamava de Volksgeist (espírito do povo).

É comum a Freyre, Holanda e Faoro a leitura de que apesar da concretização da república e de um Estado formalmente moderno, não houve entre os indivíduos a consolidação de valores universalistas demandados pela concepção de Estado moderno. ${ }^{3}$ Estes autores trabalharam com a hipótese de que na formação política e cultural do nosso país, o modelo de socialização próprio da família produziu valores que se sobrepuseram aos valores demandados aos cidadãos de um Estado democrático de direito. Os três teóricos entendem que os círculos de amizade, a gratidão, um conceito de liberdade restrito à eticidade da família acabaram impedindo o desenvolvimento de indivíduos capazes de compreender uma ideia de liberdade mais ampla. Vejamos de que modo eles trabalham com essa hipótese.

O pernambucano Gilberto Freyre pensou a "família" a partir do complexo formado pela "casa-grande" e a "senzala". Para Freyre, a relação entre senhor e escravo, casa-grande e senzala, constitui uma relação de família. E nessa relação encontramos os elementos para pensarmos as "raízes do Brasil". Freyre entende que

\footnotetext{
${ }^{3}$ Nossa proposta não se dá a partir de uma perspectiva eurocêntrica que busca apontar o "porquê" do Brasil não ter atingido o desenvolvimento político dos países europeus. Portanto, é importante salientar que alguns pressupostos da teoria política hegeliana são bem questionáveis, como por exemplo, a ideia de que o modelo de Estado constitucional europeu, em especial o Prussiano, produziu uma reconciliação do indivíduo com a totalidade. Habermas critica esse diagnóstico reconciliador de Hegel, apontando que com isso o filósofo de Jena colocou a "[...] filosofia livre da tarefa de confrontar a existência vil da vida social e política [...]" (HABERMAS, 2000, p.62). Boa parte das críticas ao pensamento de Hegel que consideramos justas advém desses pontos de sua filosofia nos quais ele vangloria o Estado prussiano de sua época e o considera a síntese perfeita entre a família e a sociedade civil. Marcuse observa que "o modo como abordou o tema nos seus últimos escritos (principalmente nos Princípios da Filosofia do Direito) fez com que já, em sua época, ele fosse rotulado de [...] o filósofo oficial do Estado prussiano, e o ditador filosófico da Alemanha" (MARCUSE, 1978, p.161)
} 
Nas casas-grandes foi até hoje onde melhor se exprimiu o caráter brasileiro; a nossa continuidade social [...]. Estudando a vida doméstica dos antepassados sentimo-nos aos poucos nos completar: é outro meio de procurar-se o "tempo perdido" [...]. (FREYRE, 2006: p. 45).

No clássico Casa-grande e Senzala, Freyre descreve em detalhes como no Brasil colonial os escravos participavam ativamente do cotidiano da casa-grande, estando presente na criação dos filhos dos senhores e na vida sexual dos moradores da casa-grande. No entanto, vemos em Casagrande e Senzala que essa organização familiar complexa é mediada por relações sádicas. O senhor exerce o seu poder de mando agindo com violência sobre a mulher, os filhos e os escravos. As sinhás mutilam as escravas por conta dos ciúmes que tem de seus maridos. Os filhos do senhor usam os escravos como brinquedos. Esse sadismo que opera dentro do núcleo familiar vai se manifestar depois na esfera política por meio do

simples e puro gosto de mando, característico de todo brasileiro nascido ou criado em casa-grande de engenho. Gosto que tanto se encontra, refinado em um senso grave de autoridade em um D. Vital, como abrutalhado, em rude autoritarismo em um Floriano Peixoto (FREYRE, 2006, p. 113).

Enquanto Freyre utiliza a noção de "mando" para discutir a constituição da identidade naciona, Sérgio Buarque de Holanda abordou as relações familiares recorrendo à "cordialidade". Holanda parte justamente da tragédia Antígona para discutir as relações entre família e Estado na formação do nosso ethos. No seu clássico Raízes do Brasil, ele diz o seguinte:

O conflito entre Antígona e Creonte é de todas as épocas e preserva-se sua veemência ainda em nossos dias. Em todas as culturas, o processo pelo qual a lei geral suplanta a lei particular faz-se acompanhar de crises mais ou menos graves e prolongadas, que podem afetar profundamente a estrutura da sociedade (HOLANDA, 1983, p. 102).

Esse conflito fundamental entre a "lei particular" e a "lei geral" ocorre no Brasil de uma maneira bem peculiar. A perspectiva de Holanda é que a "lei do Estado" (lei geral) está acima da "lei da família" (lei particular) de uma maneira meramente formal. No entanto, de maneira efetiva há uma "[...] supremacia incontestável [...] do núcleo familiar - a esfera, por excelência dos chamados 'contatos primários', dos laços de sangue e de coração" (HOLANDA, 1983, p. 106). Diante disso, "[...] as relações que se criam na vida doméstica sempre fornecem o modelo obrigatório de qualquer composição social entre nós" (HOLANDA, 1983, p. 106). O que Holanda 
entende como médium das relações no núcleo familiar é a "cordialidade", o brasileiro é caracterizado como o "homem cordial". Cordialidade aqui não é sinônimo de bondade, com o conceito de cordialidade Holanda quer indicar que no brasileiro predomina um forte emotivismo, os brasileiros tendem a julgar tudo pelo coração. Essa cordialidade vai se projetar no trato que os indivíduos têm com a coisa pública. Por exemplo, o ensaísta observa que com a formação de uma burocracia estatal, não foi fácil para os "[...] detentores das posições públicas de responsabilidade formados por tal ambiente, compreenderem a distinção fundamental entre os domínios do privado e público" (HOLANDA, 1983, p. 105). A gerência do Estado foi pensada a partir do domínio privado, isto é, a partir das relações de cordialidade geradas no núcleo familiar. Com isso,

a escolha dos homens que irão exercer funções públicas faz-se de acordo com a confiança pessoal que mereçam os candidatos, e muito menos de acordo com as suas próprias capacidades (HOLANDA, 1983, p. 106).

A formação da burocracia estatal do Estado brasileiro não foi mediada então por uma racionalidade estratégica, que traçaria os melhores meios para se atingir determinados fins, mas sim pelo emotivismo do "homem cordial" que procura favorecer aqueles que lhe são próximos. A "neutralidade" de uma razão que gerencia os assuntos do Estado teria sido "contaminada" pela cordialidade, marca característica da nossa identidade nacional, o que indicaria um forte apego do brasileiro pelo modo de socialização próprio da família.

Por fim, vemos também em Raymundo Faoro uma análise fundamental das relações entre família e Estado no contexto da formação do ethos brasileiro. Em os Donos do Poder, Faoro ao explicar a gênese do Estado brasileiro retoma uma análise de metrópole portuguesa. A coroa portuguesa formou um imenso patrimônio rural que muitas vezes se confundia com a propriedade do rei. Deste modo, "rendas e despesas se aplicam, sem discriminação normativa prévia, nos gastos de família ou em obras e serviços de utilidade geral" (FAORO, 1991, p. 20). Para Faoro, o trato da família real com o Estado como se este fosse algo privado se tornou o arquétipo que inspirou a organização e gerência da burocracia estatal no Brasil. Essa indeterminação entre o público e o privado, que constituí as raízes de uma relação patrimonialista com o Estado, colocava "os servidores numa rede patriarcal, na qual eles representam a extensão da casa do soberano" (FAORO, 1991, p. 20).

\section{Pré-modernidade ou patologia social?}

A filosofia hegeliana descreve que na família há uma socialização baseada na anulação da individualidade em prol da conservação da unidade 
familiar. Contudo, ela encontra como antítese uma forma de socialização que supervaloriza a individualidade, a sociedade civil, e isso ameaça os laços sociais, causando nos indivíduos um sentimento de abandono. $\mathrm{O}$ Estado moderno seria para Hegel a síntese entre a família e a sociedade civil, pois ele permitiria a afirmação do indivíduo sem a negação do todo, da coletividade. Além disso, nessa forma de socialização que ocorre por meio do Estado, a afetividade que mediava as relações na unidade familiar é substituída por uma "afetividade racionalizada", a saber, a solidariedade entre concidadãos. Há então na eticidade do Estado um "ganho de universalidade" em relação a eticidade da família. Por meio do direito positivo o ser humano é pensado como "pessoa universal". Deste modo, "o homem vale por ser homem, não porque seja judeu, católico, protestante, alemão ou italiano" (HEGEL, 1997, p. 185). No Estado, o indivíduo seria digno de reconhecimento por conta de suas características mais universais, e não por seus laços sanguíneos com outros indivíduos.

Tendo em vista que esse é o processo que constitui o que se denomina modernidade, as abordagens de Freyre, Holanda e Faoro parecem apontar que o Brasil está à margem da modernidade, estaríamos na sua periferia, ou teríamos somente uma modernidade de fachada em uma sociedade pré-moderna. Colocado nesses termos, é possível então denominar que esse tipo de abordagem descreve o Brasil como um "ainda não" Europa. Mas até que ponto esses autores realmente conseguiram capturar nosso Volksgeist?

Jessé Souza defende que esses autores não chegaram a descrever a identidade nacional do brasileiro, mas contribuíram de forma significativa para a construção do "mito da brasilidade". Na leitura de Souza, esse mito começa a ser construído quando Freyre formula a tese de que o Brasil é "uma sociedade pré-moderna e dominada pela emotividade e pessoalidade" (SOUZA, 2015, p.16). Posteriormente

O que Buarque acrescenta de (aparentemente) novo é a transformação da ênfase no personalismo - a emotividade como um dado psicossocial que guia as relações interpessoais de favor/proteção - típica da interpretação freyriana em ênfase no aspecto institucional e político, ou seja, supostamente patrimonial (SOUZA,2015 p.16).

A Faoro coube a tarefa de descrever de maneira erudita a história desse patrimonialismo.

A tese do livro de Faoro, Os donos do poder, é clara desde o início: sua tarefa é demonstrar o caráter patrimonialista do Estado e, por extensão, de toda a sociedade brasileira. Esse caráter patrimonialista responderia, em última instância, pela substância intrinsecamente não democrática, particularista e baseada em privilégios que sempre teria marcado o exercício 
do poder político no Brasil. Faoro procura comprovar sua hipótese buscando raízes que se alongam até a formação do Estado português no remoto século XII de nossa era (SOUZA, 2015, p.29).

Esses três autores, de acordo com Souza, construíram uma interpretação "culturalista conservadora" da sociedade brasileira, operando uma releitura do racismo científico.

\begin{abstract}
Assim, do mesmo modo que o "racismo científico", que possuía projeção internacional até a década de 1920, partia da superioridade "racial" dos povos brancos e de olhos azuis, a versão "culturalista" do racismo parte da superioridade de certo "estoque cultural" das sociedades do "Atlântico Norte" como fundamento da "superioridade" dessas sociedades (SOUZA, 2015, p.10).
\end{abstract}

Para Souza as diferenças entre povos do sul e povos do norte que antes eram estabelecidas a partir de critérios raciais e biológicas, agora ocorre por meio de categorias cognitivas e morais. O norte é descrito como "moderno", "impessoal", "universalista" e "racional". O sul é a representação do "arcaico", "pessoal", "particularista" e "emotivo". Uma das teses defendidas por Souza em A tolice da inteligência Brasileira é que a interpretação do Brasil realizada por esses pensadores se tornou hegemônica na academia, na televisão, no parlamento e nos jornais. Chegando ao ponto em que "no mundo cotidiano essas ideias parecem não ter autoria e ser tão 'naturais' como ter-se duas pernas e dois olhos" (SOUZA, 2015, p.13).

A crítica realizada por Souza aos clássicos do pensamento social brasileiro é instigante, e o autor consegue construir bons argumentos contra o mito da brasilidade. A Tolice da inteligência brasileira é um trabalho que mereceria uma discussão mais profunda em outro momento. Contudo, aqui queremos lançar uma proposta de trabalho que talvez contrarie o o estudo de Souza.Acreditamos que os pressupostos das reflexões de Freyre, Holanda e Faoro talvez não devam ser completamente descartas, sendo possível reconstruí-las mais uma vez. Não se trata de defender que estes pensadores conseguiram desvendar a identidade nacional do povo brasileiro. Nossa hipótese é que tais autores intuíram de maneira indireta um tipo de "patologia social" não identificada por nenhum frankfurtiano. A reconstrução das ideias desses pensadores e o subsídio de pesquisas empíricas ainda podem contribuir para a elaboração de um diagnóstico de época original e plausível. Se essa proposta for levada a sério, talvez ela permita identificar até os impulsos para uma emancipação deste tipo de patologia. 


\section{Referências bibliográficas}

BOBBIO, Norberto. Estudos sobre Hegel: direito, sociedade civil e Estado. São Paulo: Editora Brasiliense, 1989.

BORNHEIM, Gerd A. Dialética - teoria e práxis (ensaio para uma crítica da fundamentação ontológica da dialética). São Paulo: Ed. Globo, 1977. CASSIRER, Ernst. O mito do Estado. Rio de Janeiro: Zahar editores, 1976. COULANGES, Fustel de. A cidade antiga. São Paulo: Martin Claret, 2009. FAORO, Raymundo. Os donos do poder. Porto Alegre: Ed. Globo, 1991. FREYRE, Gilberto. Casa-grande \& Senzala: formação da família brasileira sob o regime de economia patriarcal. São Paulo: Global, 2006.

HABERMAS, Jürgen. $O$ discurso filosófico da modernidade: doze lições. São Paulo: Martins Fontes, 2000.

HEGEL, Georg Wilhelm Friedrich. Fenomenologia do Espírito. 7.ed.rev. Rio de Janeiro: Vozes, 2002.

Brasília, 2008. Filosofia da história. Brasília: Editora Universidade de Princípios da filosofia do direito. São Paulo: Ed. ícone, 2005.

HOLANDA, Sérgio Buarque de. Raízes do Brasil. Rio de Janeiro: Ed. José Olympio, 1983.

HONNETH, Axel. Sofrimento de indeterminação: uma reatualização da filosofia do direito de Hegel. São Paulo: Ed. Esfera Pública, 2007.

MARCUSE, Hebert. Razão e revolução: Hegel e o advento da teoria social. Rio de Janeiro: Paz e Terra, 1978.

SÓFOCLES. Antígona. Rio de Janeiro: DIFEL, 2013. 